\title{
Causality between Energy Consumption and Economic Growth: The Case of Pakistan
}

\section{Qazi Muhammad Adnan Hye* and Sana Riaz}

\begin{abstract}
This study seeks to determine the direction of causality between energy consumption (EC) and economic growth (EG), using annual data from 1971 to 2007. In our empirical analysis, we implement a boundstesting approach to co-integration and an augmented form of the Granger causality test to identify the direction of the relationship between these variables both in the short and long run. Our findings suggest bidirectional causality between EG and EC in the short run; in the long run we find unidirectional causality from $E G$ to $E C$. EC does not lead to $E G$ in the long run because higher energy prices (oil prices) increase the cost of business, leading to a negative effect on EG. Additionally, when energy prices fluctuate, they create uncertainty that also affects economic growth. The study recommends direct investment in local energy resources.
\end{abstract}

JEL Classification: O10, C1.

Keywords: Economic Growth, Energy Consumption, Pakistan.

\section{Introduction and Literature Review}

Energy plays a crucial role in the economic development of a country. It enhances the productivity of factors of production and increases living standards. It is extensively recognized that economic development and energy consumption are interdependent. ${ }^{1}$ The energy crisis of the 1970 s and persistently high energy prices, particularly oil prices, have had a significant impact on the economic activity of developing economies. The key question in energy economics, however, is whether economic growth (EG) leads to energy consumption (EC) or whether EC leads to EG. Although the causal relationship between EC and economic growth (EG) has been widely studied over the last 3 decades, the empirical evidence is not without controversy. Using regression analysis, Pachauri (1977) and Tyner (1978) found that there was a strong correlation between economic development and EC in India.

\footnotetext{
* Applied Economics Research Centre, University of Karachi.

${ }^{1}$ See Alam and Butt (2002).
} 
Yu and Choi (1985) estimated the casual relationship between the EC and gross national product (GNP) of five countries, concluding that there was unidirectional causality from EC to GNP in the Philippines, and reverse causality from GNP to EC in South Korea, but no causality in the USA, UK, and Poland. Cheng (1995 and 1997), employing a multivariate approach, concluded that there was no evidence of causality from EC and capital to EG in the USA, Mexico, and Venezuela. Stern (2000) found a co-integrated relationship between gross domestic product (GDP), capital, labor, and EC in the USA.

In the case of Pakistan, Riaz (1984) investigated the relationship between EC and EG using log linear regression analysis. The regression analysis of the energy-growth relationship has shown independence between socioeconomic variables and EC. Masih and Masih (1996) found a co-integrated relationship between EC and GDP in India, Pakistan, and Indonesia, but no such evidence in the case of Malaysia, Singapore, and the Philippines. Yang (2000) investigated the causal relationship between GDP and EC-including that of coal, natural gas, and electricityanalyzing the aggregate as well several disaggregated categories and found a bidirectional causality between total EC and GDP in India; in the case of Pakistan and Indonesia, GDP was found to cause EC. Anjum and Butt (2001) found that EG caused total EC, but further investigation indicated that EG did not lead to growth in petroleum consumption, while in the case of the gas sector, neither EG nor gas consumption affected each other. In the power sector, however, electricity consumption was found to lead to EG without feedback. Finally, EC was found to directly cause employment. Alam and Butt (2002) concluded that EC, EG, capital, and labor were co-integrated and that causality ran from EC to EG in the short and long run.

The objective of this paper is to re-estimate the causality between EC and EG in Pakistan as a developing economy, by employing the recently advanced co-integration technique. Section II describes data and methodology, Section III discusses empirical results, followed by a conclusion and policy implications in Section IV.

\section{Data and Methodology}

This study uses annual data from 1971 to 2007 . GDP is measured in millions of Pakistan rupees and EC in kiloton (kt) of oil equivalent. GDP is used as a proxy variable for EG. Data for both variables are taken from 
World Development Indicators. ${ }^{2}$ This empirical analysis adopts a three-stage procedure to test the direction of causality between EC and EG.

In the first stage, the integration order of the variables is established by implementing the Ng-Perron (2001) unit root test. ${ }^{3}$ In describing the $\mathrm{Ng}$-Perron unit test, we start with the augmented Dickey-Fuller (ADF) test. ${ }^{4}$

$\Delta y_{t}=\alpha y_{t-1}+x_{t}^{\prime} \delta+\beta_{1} y_{t-1}+\beta_{2} \Delta y_{t-2}+\ldots \ldots+\beta_{p} \Delta y_{t-p}+v_{t} \quad 1$

The null hypothesis of a unit root involves testing $\alpha=0$ against the alternative hypothesis $\alpha<1$ using the conventional t-test. Since the statistic does not follow the conventional student's t-distribution, Dickey and Fuller (1979) and Mackinnon (1996), among others, simulate the critical values. The ADF tests, can include a constant and / or a linear time trend. Elliot, Rothemberg and Stock ( ERS hereinafter) (1996) modify the ADF tests for two cases-one with a constant and the other with a constant and a trend, as follows. First, a quasi-difference of $y_{t}$ in defined. The quasi-difference of $y_{t}$ depends on the value of a representing the specific point against which the null hypothesis below is tested.

$$
d\left(\frac{y_{t}}{a}\right)=y_{t} \text { if } t=1 \text { and } d\left(\frac{y_{t}}{a}\right)=y_{t}-a y_{t} \text { if } t>1
$$

Second, quasi-differenced data $d\left(y_{t} / a\right)$ is regressed on the quasidifference as follows:

$d\left(\frac{y_{t}}{a}\right)=d\left(\frac{x_{t}}{a}\right)^{\prime} \delta(a)+\eta_{t}$

Where $x_{t}$ contains a constant or a constant and a trend. Let $\hat{\delta}(a)$ be the OLS estimate of $\delta(a)$. For a, the ERS method recommends using $\alpha=\bar{\alpha}$ where $\bar{\alpha}=1-7 / T$ if $x_{t}=\{1\}$ and $\bar{\alpha}=1-13.5 / T$ if $x_{t}=\{1, \mathrm{t}\}$. GLS detrended data, $y_{t}^{d}$, are defined as follows: $y_{t}^{d} \equiv y_{t}-x_{t}^{\prime}$. According to the ERS method, GLS detrended $y_{t}^{d}$ substituted for $y_{t}$.

$$
\Delta y_{t}^{d}=\alpha \Delta y_{t-1}^{d}+\beta_{1} \Delta y_{t-2}^{d} \Delta y_{t-1}+\cdots \cdots+\beta_{P} \Delta y_{t-P}^{d}+v_{t}
$$

\footnotetext{
${ }^{2}$ EG and EC are transformed into natural logarithms prior to econometric estimates.

3 The advantages of the Ng-Perron tests are that it allows a good size and power, and is particularly suitable for small samples.

${ }^{4}$ Dickey and Fuller (1979, 1981).
} 
As in the ADF test, the GLS unit root test involves the test on the coefficient a. The ERS point optimal test is as follows. Let the residuals from equation (2) be $\hat{\eta}_{t}(a)=d\left(y_{t} / a\right)=d\left(x_{t} / a\right)^{\prime} \hat{\delta}(\bar{\alpha})$ and let the sum of squared residuals, $\operatorname{SSR}(\alpha)=\hat{\eta}_{t}^{2}(\alpha)$. The null hypothesis for the point optimal test is $\alpha=1$ and the alternative hypothesis is $\alpha=\bar{\alpha}$. The test statistic is $P_{t}=\left(\operatorname{SSR}(\bar{\alpha})-S S R(1) / f_{0}\right.$ where $f_{0}$ is an estimator of the residual spectrum at frequency zero. The four $\mathrm{Ng}$-Perron tests involve modifications of the following four unit root tests: Phillips-Perron $Z_{a}$ and $Z_{t}$, Bhargava $R_{1}$, and the ERS optimal point test. The tests are based on GLS detrended data, $\Delta y_{t}$. First, let us define $k=\sum_{t-2}^{T}\left(y_{t-1}^{d}\right)^{2} / T^{2}$.

The four statistics are listed below:

$$
\begin{aligned}
& M Z_{\alpha}^{d}=\left(\left(T^{1} y_{T}^{d}\right)^{2}-f_{0}\right) / 2 k \\
& M Z_{t}^{d}=M Z_{\alpha} \times M S B \\
& M S B^{d}=\left(k / f_{0}\right)^{1 / 2} \\
& M P_{T}^{d}=\left(\bar{c}^{2} k-\bar{c} T^{1}\right)\left(y^{d} T\right)^{2} / f_{0} \text { if } x_{t}=\{1\} \\
& \text { and } M P_{T}^{d}=\left(\bar{c}^{2} k+(1-\bar{c}) T^{1}\right)\left(y^{d} T\right)^{2} / f_{0} \text { if } x_{t}=\{1, t\} \\
& \text { Where } \bar{c}=-7 \text { if } x_{t}=\{1\} \text { and } \bar{c}=-13.5 \text { if } x_{t}=\{1, t\}
\end{aligned}
$$

As with most other tests, the null hypothesis of the unit root cannot be rejected if the test statistic is higher than the critical value.

The second stage involves testing for the existence of a long-run relationship between EG and EC within a univariate framework. In the last two decades, several econometric procedures have been employed to investigate the co-integrated relationships among macroeconomic variables. With regard to univariate co-integration approaches, there are several examples, including Engle and Granger (1987) and the fully modified OLS procedures of Phillips and Hansen (1990). There are also many examples of multivariate co-integration procedures, including Johansen (1988), Johansen and Juselius (1990), and Johansen's (1996) full information maximum likelihood technique. 
A recently advanced co-integration approach, known as the autoregressive distributed lag (ARDL) [Pesaran et al (2001)], has become popular among researchers. In Pesaran et al (2001), the co-integration approach, also known as the bounds testing method, ${ }^{5}$ is used to test the existence of a co-integrated relationship among variables. The procedure involves investigating the existence of a long-run relationship in the form of an unrestricted error correction model for each variable as follows:

$$
\begin{aligned}
& \Delta \operatorname{Ln}(E G)_{t}=\lambda_{0 E G}+\sum_{i=0}^{n} \lambda_{i E G} \Delta \operatorname{Ln}(E G)_{t-i}+\sum_{i=0}^{n} \lambda_{i E G} \Delta \operatorname{Ln}(E C)_{t-i}+ \\
& \alpha_{1 E G} \operatorname{Ln}(E G)_{t-1}+\alpha_{2 E G} \operatorname{Ln}(E C)_{t-1}+v_{1 t} \\
& \Delta \operatorname{Ln}(E C)_{t}=\lambda_{0 E C}+\sum_{i=0}^{n} \lambda_{i E C} \Delta \operatorname{Ln}(E C)_{t-i}+\sum_{i=0}^{n} \lambda_{i E C} \Delta \operatorname{Ln}(E G)_{t-i}+ \\
& \alpha_{1 E C} \operatorname{Ln}(E C)_{t-1}+\alpha_{2 E C} \operatorname{Ln}(E G)_{t-1}+v_{2 t}
\end{aligned}
$$

Where $\ln (E G)$ is the natural logarithm of GDP, and $\ln (\mathrm{EC})$ is the natural logarithm of EC. The F-tests are used to test the existence of long-run relationships. The F-test used for this procedure, however, has a nonstandard distribution. Thus, the Pesaran et al (2001) approach computes two sets of critical values for a given significance level. One set assumes that all variables are $I(0)$ and the other set assumes they are all $I(1)$. If the computed F-statistic exceeds the upper critical bounds value, then the $H_{0}$ (null hypothesis) is rejected. If the F-statistic falls within the bounds set, then the test becomes inconclusive. If the F-statistic falls below the lower critical bound value, it implies no co-integration. When a long-run relationship exists, the F-test indicates which variable should be normalized. The null hypothesis of equation (6) is $\left\langle H_{0}=\alpha_{1 E G}=\alpha_{2 E G}=0\right\rangle$. This is denoted as $F_{E G}\langle\operatorname{Ln}(E G) \mid \operatorname{Ln}(E C)\rangle$. In equation (7), the null hypothesis is $\left\langle H_{0}=\alpha_{1 E C}=\alpha_{2 E C}=0\right\rangle$, which is represented by $F_{E C}\langle\operatorname{Ln}(E C) \mid \operatorname{Ln}(E G)\rangle$.

\footnotetext{
${ }^{5}$ It has certain econometric advantages compared with other single co-integration procedures. They are as follows: i) endogeneity problems and inability to test hypotheses on the estimated coefficients in the long-run associated with the Engle-Granger method are avoided; ii) the long and short-run parameters of the model in question are estimated simultaneously; iii) the ARDL approach to testing for the existence of a long-run relationship between the variables in levels is applicable irrespective of whether the underlying regressors are purely $I(0)$, purely $I(1)$, or fractionally integrated; iv) It is superior in small sample.
} 
The third stage entails forming standard Granger-type causality tests augmented by a lagged error-correction term. The Granger representation theorem suggests that there will be Granger causality in at least one direction if there exists a co-integrated relationship among the variables in equations (6) and (7), providing that they are integrated to the order of 1. Engle and Granger (1987) show that the Granger causality test, which is conducted in first difference via a vector auto-regression (VAR), will be misleading in the presence of co-integration. Therefore, including an additional variable in the VAR system, such as an error-correction term, helps capture the long-run relationship. An augmented form of the Granger causality test involving an error-correction term is formulated in a vector error-correction model (VECM), as follows:

$\left[\begin{array}{l}\Delta \ln E G \\ \Delta \ln E G\end{array}\right]=\left[\begin{array}{l}\Gamma_{1} \\ \Gamma_{2}\end{array}\right]+\sum_{i=1}^{p}\left[\begin{array}{lll}n_{11 i} & n_{12 i} & n_{13 i} \\ n_{21 i} & n_{22 i} & n_{23 i}\end{array}\right]\left[\begin{array}{l}\Delta \ln E G_{t-i} \\ \Delta \ln E G_{t-i}\end{array}\right]+\left[\begin{array}{l}\Omega_{1} \\ \Omega_{2}\end{array}\right]\left[\begin{array}{l}E C_{t-1}\end{array}\right]+\left[\begin{array}{l}\Psi_{1} \\ \Psi_{2}\end{array}\right] 8$

$\mathrm{EC}_{\mathrm{t}-1}$ is the error correction term that is derived from the long-run relationship. The Granger causality test can be applied to equation (8) as follows: (i) by checking the statistical significance of the lagged differences of the variables for each vector: this is a measure of short-run causality; and (ii) by examining statistical significance of the error-correction terms for the vector which shows the existence of a long-run relationship.

\section{Empirical Results}

All time series data show some trend. When working with time series data, the first question to ask is whether or not the series is stationary. A stochastic process is said to be stationary if its mean and variance are constant over time, and if the covariance exists between the two time periods and not the actual time at which the covariance is computed. To test the stationary of the variables the Ng-Perron unit root test is applied for EC and EG. ${ }^{6}$ The results of Table-1 indicate that $\ln (\mathrm{EG})$ and $\ln (\mathrm{EC})$ are $\mathrm{I}(1)$ variables at a $1 \%$ significance level.

\footnotetext{
${ }^{6}$ Mostly in literature, the order of integration explore by using the ADF (Dicky \& Fuller, 1979) and P-P (Philip \& Perron, 1988) unit root tests. Due to their poor size and power properties, both tests are not reliable for small sample data set (Dejong et al, 1992 and Harris, 2003). So this study uses Ng-Perron unit root test.
} 
Table-1: Ng-Perron Unit Root Test

\begin{tabular}{|c|c|c|c|c|}
\hline \multicolumn{5}{|c|}{ Ng-Perron at Level with Constant and Trend } \\
\hline & MZa & MZt & MSB & MPT \\
\hline $\ln (E C)$ & -1.25 & -0.48 & 0.38 & 36.42 \\
\hline $\ln (E G)$ & -8.38 & -1.89 & 0.22 & 11.33 \\
\hline \multicolumn{5}{|c|}{ Ng-Perron at $1^{\text {st }}$ Difference With Constant and Trend } \\
\hline$\Delta \ln (E C)$ & $-21.21^{*}$ & -3.24 & 0.15 & 4.35 \\
\hline$\Delta \ln (E G)$ & $-568.62 *$ & -16.81 & 0.02 & 0.24 \\
\hline
\end{tabular}

* Significant at $1 \%$.

Equations (6) to (8) were estimated in two stages. In the first stage of the ARDL producer, the order of lags on the first differenced variables was obtained from unrestricted VAR by means of the Akaike Information Criterion (AIC) and Schwarz-Bayesian Criterion (SBC). Both lag selection criterion indicates that the optimal lag level is 3 years.

Table-2: Lags Selection Criterion

\begin{tabular}{|c|c|c|c|c|}
\hline Lag & & AIC & & SBC \\
\hline 1 & & -2.86 & & -2.77 \\
\hline 2 & & -10.14 & & -9.80 \\
\hline 3 & 1) & $-10.27 *$ & 2) & $-9.81 *$ \\
\hline
\end{tabular}

An F deletion test was applied to equations (6) and (7) in order to test the existence of a long-run relationship. The results of bounds testing are presented in Table-3. As can be seen in Table-3, it is clear that there is a long-run relationship between the variables when EC is the dependent variable because its F-statistic exceeds the upper bound critical value at a $5 \%$ level of significance. The null hypothesis of equation (6) however, cannot be rejected. Thus, the bounds test result confirms that long-run unidirectional causality runs from EG to EC. At the bottom of Table-3, the estimate of the co-integrated equation shows a positive elasticity (equal to 0.33 ) for EC with respect to EG. 
Table-3: Calculated F-Statistic ${ }^{7}$

\begin{tabular}{lcc}
\hline & Lag 2 & Lag 3 \\
\hline$F_{E G}\langle\operatorname{Ln}(E G) \mid \operatorname{Ln}(E C)\rangle$ & 1.48 & 0.94 \\
$F_{E C}\langle\operatorname{Ln}(E C) \mid \operatorname{Ln}(E G)\rangle$ & 5.11 & 6.55 \\
Long-Run Elasticity (Co-Integrated Equation) & \\
$\operatorname{Ln}(\mathrm{EC})=1.69+0.33 \operatorname{Ln}(\mathrm{EG})$ & \\
T-ratio (8.87) (46.94) & \\
\hline
\end{tabular}

Table-4 shows the results of short- and long-run Granger causality within the VECM framework. The short-run causal effects are demonstrated through the F-statistics of the explanatory variables and long run causality is tested with the help of statistical significance and sign of the error correction term. The coefficient of the lagged error-correction term is significant (at a 1\% level of significance) with the expected sign (negative), when the $\ln (\mathrm{EC})$ is the dependent variable, which is also confirmed by the result of the bounds test.

Table-4: Granger Causality Test

\begin{tabular}{lccc}
\hline \multicolumn{3}{c}{ F-statistics } \\
Dependent Variable & $\Delta \ln (E G)$ & $\Delta \ln (E C)$ & $(\mathbf{E C M})_{\mathbf{t}-\mathbf{1}}(\mathbf{t}$-statistic) \\
\hline$\Delta \ln (E G)$ & - & 10.52 & -0.33 \\
& & $(0.00)$ & $(0.35)$ \\
$\Delta \ln (E C)$ & 3.25 & - & -0.13 \\
& $(0.05)$ & & $(0.00)$ \\
Causality Inference: $E C \Rightarrow E G$ and $E G \Rightarrow E C$ & in the short run \\
$E G \Rightarrow E C \quad$ in the Long run
\end{tabular}

This implies that EG Granger causes EC in the long run and that the direction of causality runs interactively through the error-correction term. On other hand, there is bidirectional causality between EC and EG in the short run.

\footnotetext{
${ }^{7}$ The critical value ranges of F-statistics are $3.96-4.53$ and $3.21-3.74$ at $5 \%$ and $10 \%$ level of significances, respectively. See Paresh Kumar Narayan (2005).
} 


\section{Conclusion and Policy Implications}

The objective of this study was to determine the direction of causality between EG and EC, by using the co-integration approach known as the Autoregressive Distributed Lag (ARDL) [Pesaran et al (2001)] and an augmented form of the Granger causality test. Our main findings were as follows. First, we found that, by using the ARDL, there was one cointegrated relationship between the two variables when EC was the dependent variable. Second, we investigated the direction of causality between the variables using the Granger causality-testing producer, and found that changes in EG cause changes in EC in the short- and long run. Moreover, EC will cause EG in the short run but not in the long run.

Our findings have the following policy implications. EC in the form of oil consumption will Granger cause EG only in the short run, not the long run. On the other hand, EG will increase EC. Pakistan initially met only $18 \%$ of its energy needs from indigenous production, had to import the remaining $82 \%$ and pay international prices. The policy implication of this paper is that Pakistan will need to continue investing in the energy sector, particularly in natural gas, coal, wind, hydroelectricity, and nuclear power. This will reduce its import burden. On the demand side, consumers should be made aware of the importance of efficient use of oil, particularly given our finding that oil consumption does not contribute to EG in the long run. 


\section{References}

Alam and Butt, 2002, "Causality between Energy Consumption and Economic Growth in Pakistan: An Application of Co-Integration and Error Correction Modeling Techniques." Pacific and Asian Journal of Energy, Vol. 12, 2 : 151-165.

Anjum and Butt, 2001, "The Relationship between Energy Consumption and Economic Growth in Pakistan." Asia-Pacific Development Journal, Vol. 8, 2 : 101-110.

Cheng, S. Benjamin, and Tin Wei Lai, 1997, "An Investigation of CoIntegration and Causality between Energy Consumption and Economic Activity in Taiwan Province of China." Energy Economics, Vol. 19 : 435-444.

Cheng, 1985, "An Investigation of Co-Integration and Causality between Energy Consumption and Economic Growth." Journal of Energy and Development, Vol. 21, 1 : 73-84.

Cheng, 1997, "Energy Consumption and Economic Growth in Brazil, Mexico and Venezuela: A Time Series Analysis." Applied Economic Letters, Vo1. 4, 8 : 476-674.

Chishti, S., and Fakhre F. Mahmud, 1990, "The Demand for Energy in the Large-Scale Manufacturing Sector of Pakistan.” Energy Economics, Vol. 12, : 251-254.

Dejong, D. N., J. C. N Ankervis., N. E. Savin, and C. H. Whiteman, 1992, "The Power Problems of Unit Root Tests in Time Series with Autoregressive Errors.” Journal of Econometrics, Vo1. 53 : 323-343.

Dickey, D. A., and W. A. Fuller, 1979, "Distribution of the Estimator for Autoregressive Time Series with a Unit Root." Journal of the American Statistical Association, Vo1. 74 : 427-431.

Dickey, D. A and W. A. Fuller, 1981, "Likelihood Ratio Statistics for Autoregressive Time Series with a Unit Root.” Econometrica, Vol. 49 : 1052-1072. 
Elliott. G., T. J. Rothenberg, T. J. and J. H. Stock, J. H., 1996, "Efficient Tests for an Autoregressive Unit Root.” Econometrica, Vol. 64 : 813-836.

Engle, R. F., and C. W. J. Granger, 1987, "Co-Integration and Error Correction Estimation and Testing." Econometrica, Vol. 55 : 251276.

Erol, U., and E. S. H. Yu, 1987, "On the Relationship between Energy and Income for Industrialized Countries." Journal of Energy and Employment, Vo1. 13 : 113-122.

Ero1, U. and E. S. H. Yu, 1987, "Time Series Analysis of the Causal Relationships between U.S. Energy and Employment.” Resources and Energy, Vo1. 16 : 75-89.

Granger, C. W. J., 1969, "Investigating Causal Relations by Econometrics Models and Cross Spectral Methods.” Econometrica, Vol. 37 : 424438 .

Harris, R. D. F., and E. Tzavalis, 1999, "Inference for Unit Roots in Dynamic Panels where the Time Dimension is Fixed." Journal of Econometrics, Vo1. 91 : 201-226.

Hwang, Dennis, B. K., Gun-Bure1, 1991, "The Causal Relationship between Energy and GNP: The Case of Taiwan Province of China." Journal of Energy and Development, Vo1. 16 : 219-226.

Irfan, Mohammad M., 1982, "Wages, Employment and Trade Unions in Pakistan.” Pakistan Development Review, Vol. 21, 1 : 49-68.

Johansen, S., 1991, "Estimation and Hypothesis Testing of Co-Integration Vectors in Gaussian Vectors Autoregressive Models.” Econometrica, Vol. $59:$ 1551-1580.

Johansen, S., and K. Juselius, 1990, "Maximum Likelihood Estimation and Inference on Co-Integration with Applications to the Demand for Money." Oxford Bulletin of Economics and Statistics, Vo1. 52 : 169210.

Kraft, J., and A. Kraft, 1978, "On the Relationship between Energy and GNP.” Journal of Energy and Development, Vo1. 3 : 401-403. 
Mackinon, J. G., 1996, "Numerical Distribution Functions for Unit Root and Co-Integration Tests.” Journal of Applied Economics, Vol. 11 : 601618.

Masih, A. M. M., and R. Masih R., 1996, "Energy Consumption, Real Income and Temporal Causality: Results from a Multi-Country Study based on Co-Integration and Error Correction Modeling Techniques.” Energy Economics, Vo1. 18, 3 : 165-183.

Ng, S. P., 2001, "Lag Length Selection and the Construction of Unit Root Test with Good Size and Power." Econometrica, Vo1. 69 : 15191554.

Pachauri, R. K., 1977, Energy and Economic Development in India. New York: Praeger Publishers.

Perron. P., 1988, "The Great Crash, the Oil Prices Shock and the Unit Root Hypothesis.” Econometrica, Vo1. 57 : 1361-1401.

Pesaran, M. H., Y. Shin, and R. J. Smith, 2001, "Bounds Testing Approaches to the Analysis of Level Relationships." Journal of Applied Econometrics, Vo1. 16 : 289-226.

Phillps, P. C. B., and B. E. Hansen, 1990, "Statistical Inference in Instrumental Variables Regression with I (1) Process." Review of Economic Studies, Vo1. 57 : 99-125.

Riaz, T., 1984, "Energy Consumption and Economic Growth." Pakistan Development Review, Vo1. 23 : 431-453.

Stern, D. I., 2000, "A Multivariate Co-Integration Analysis of the Role of Energy in the US Macro Economy.” Energy Economics Review, Vol. $62,4: 540-552$.

Tyner, W. E., 1978, Energy Resources and Economic Development in India. Boston: Martinus Nijhoff Social Sciences Division.

Yang, H. Y., 2000, "A Note on the Causal Relationship between Energy and GDP in Taiwan.” Energy Economics, Vo1. 22, 3 : 309-317.

Yu, S. H. and J. Y. Choi, 1985, "The Causal Relationship between Energy and GNP: An International Comparison”. Journal of Energy and Development, Vo1. 11, 2 : 249-272. 
Appendix

A. Descriptive Statistic and Correlation Matrix

\begin{tabular}{lcc}
\hline \multicolumn{3}{c}{ Descriptive Statistic } \\
& $\operatorname{Ln}(\mathbf{Y})$ & $\ln (\mathrm{EG})$ \\
\hline Mean & 27.28 & 10.55 \\
Median & 27.30 & 10.60 \\
Maximum & 29.51 & 11.24 \\
Minimum & 24.64 & 9.76 \\
Std. Dev. & 1.469 & 0.47 \\
Skewness & -0.14 & -0.16 \\
Kurtosis & 1.88 & 1.66 \\
Correlation Matrix & & \\
& $\ln (\mathbf{Y})$ & $\ln (\mathrm{EG})$ \\
$\ln (\mathrm{Y})$ & 1 & - \\
$\ln (\mathrm{EG})$ & 0.99 & 1 \\
\hline
\end{tabular}

B. Natural Logarithm of Economic Growth (lnEG) and Natural Logarithm of Energy Consumption (lnEC)

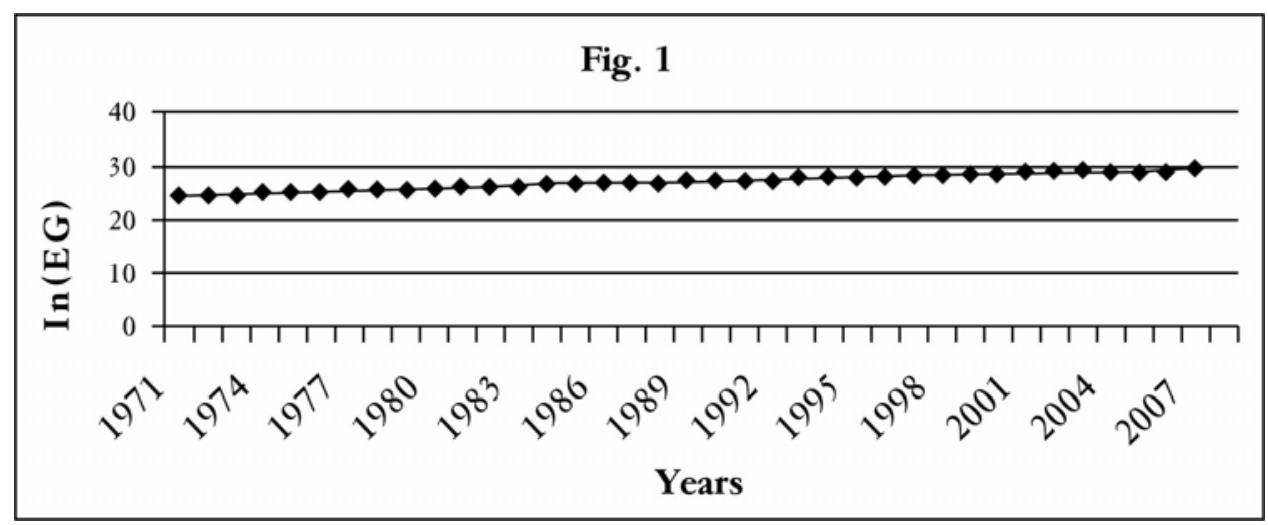




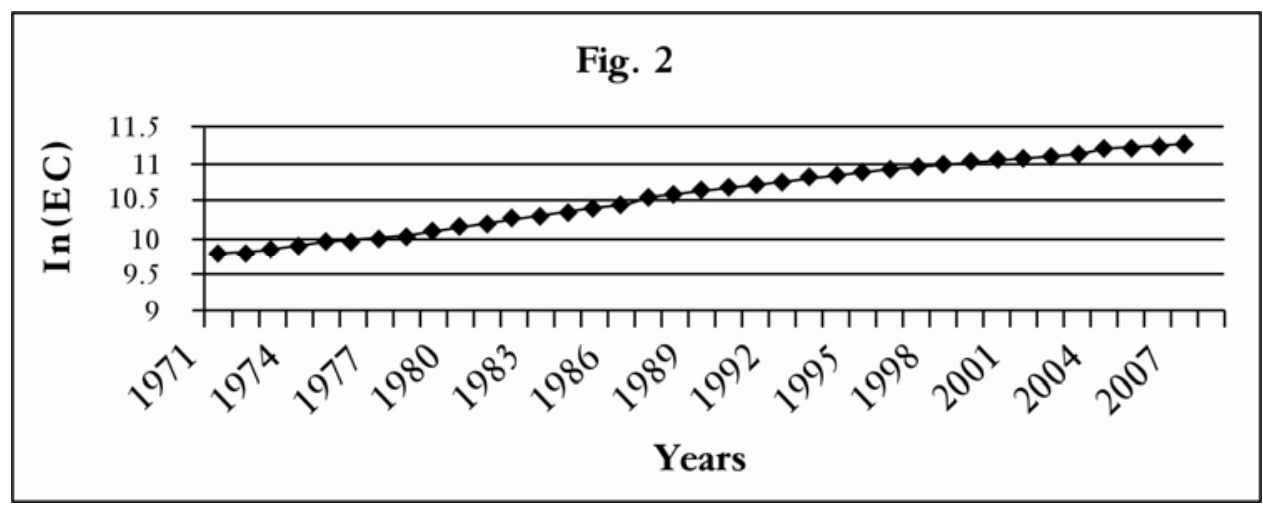

